\title{
Türkiye'de Meydana Gelen Su Sporları Kazalarının İncelenmesi
}

\author{
Burak Uyanık \\ İstanbul Teknik Üniversitesi \\ Gemi İnşaatı ve Deniz Bilimleri Fakültesi \\ orcid.org/ 0000-0001-9975-4977
}

\author{
Nuray Türker* \\ Karabük Üniversitesi \\ Safranbolu Turizm Fakültesi \\ orcid.org/0000-0001-5701-5674
}

\author{
Barış Barlas \\ İstanbul Teknik Üniversitesi \\ Gemi İnşaatı ve Deniz Bilimleri Fakültesi \\ orcid.org/ 0000-0002-5846-2369
}

\section{$\ddot{O} z$}

Gönderilme Tarihi 27.06.2019

Kabul Tarihi 09.09 .2019

Türkiye'de kıyı turizmi diğer bir ifade ile deniz-kum-güneş turizmi Türk turizm sektörünün en önemli pazarın oluşturmaktadır. Her geçen gün artan turist sayısı Türkiye ekonomisi açısından büyük önem taşımaktadır. Ancak yaz döneminde gerçekleşen su sporları kazaları kıyı turizmine gölge düşürmektedir. Bu kazaların başında sürat teknesi ve jet-ski kazaları gelmektedir. Bu çalışmada 1997-2019 yılları arasında Türkiye'de meydana gelen su sporları kazaları incelenmiş ve sık görülen kazalar üzerinden bir değerlendirme yapılmıştır. Bu kapsamda internet sayfalar ve gazete haberlerinde yer alan kaza haberleri ayrintıl olarak incelenmiş, kazaların meydana gelme sebepleri, bu kazaların meydana geldiği şehirler, ölümcül kazaların sıklık dereceleri, kazaların yaşlara göre dağılımı, kazaların meydana geldiği günler ve kazalardaki kadınerkek ölüm oranları üzerine bir değerlendirme yapılmıştır. Çalışmada ayrıca kazaların en aza indirilmesi ve can ve mal kayıplarımın önlenmesi için çeşitli çözüm önerileri sunulmuştur.

Anahtar Kelimeler: Su Sporları Kazaları, Kıyı Turizmi, Sürat Teknesi, Jet ski, Türkiye

\section{Examination of Water Sports Accidents in Turkey}

\section{Abstract}

Coastal tourism in Turkey, in other words, sea-sand-sun tourism is the most important market of the Turkish tourism industry. Increasing the number of tourists is of utmost importance for Turkish economy. However, water sports accidents that occur in the summer season have a negative impact on coastal tourism. Speed boat and jet-ski accidents are the most important accidents. This study examines the water sports accidents occurred in Turkey between the years 1997-2019 and evaluates the frequent accidents. In this context, the accident news in the internet pages and newspaper's websites were examined elaborately and the reasons for the accidents, the cities where these accidents occurred, the frequency of fatal accidents, the distribution of the accidents according to the ages, the days of the accidents and female-male death rates in these accidents were evaluated. Besides, various solutions were proposed to minimize the accidents, to prevent loss of life and property in the study.

Keywords: Water Sports Accidents, Coastal tourism, Speed boat, Jet ski, Turkey.

\section{Giriş}

Üç tarafı denizlerle çevrili olan Türkiye, denizde yapılan faaliyetler (deniz araçları ile denizde, kıyıda, denizin üzerinde, altında yapılan faaliyetler, su sporları) bakımından turistlere önemli imkânlar sunmaktadır. Özellikle kıyı turizminin ön planda olduğu Antalya, Bodrum, Marmaris, Çeşme v.b.) yapılan su sporları aktiviteleri 
önemli rekreatif etkinliklerdir. Su sporları, dalış turizmi ve su üstü sporların gelişmesi ile önemli bir rekreatif faaliyet haline gelmiştir.

Su sporları denizde, göllerde, göletlerde, nehirlerde, kanallarda ve havuzlarda yapılan sportif faaliyetleri kapsamaktadır (Paker, 2013). Suyun akışkan bir özelliğe sahip olması su üstü ve su altında pek çok su sporu faaliyetinin yapılabilmesine olanak sağlamaktadır. Suda yüzme, atlama ve serbest dalma gibi herhangi bir araca ihtiyaç olmadan yapılabilen sporlar olduğu gibi rüzgâr sörfü, su kayağı ve jet ski gibi bir araca bağlı olarak yapılanlar ile su altında uzun süre kalabilmek için su altında nefes almayı sağlayan ekipmanlarla yapılan su sporları da bulunmaktadır. Su sporlarının rüzgâr sörfü (Windsurf), dalga sörfü (Wavesurf), skimboarding, uçurtma sörfü (Kitesurf), yelken, parasailing, su kayağı, wakeboard, wakeskate, kneeboard, wakesurfing, hidrofil su kayağı, skurfing, kablolu su kayağı, sürat teknesine, amfibi araba, amfibi atv, jet ski, flyboard, seabreacher, kano, deniz bisikleti, shuttle bike, su kuşu (Waterbird), banana, hamburger, mable, flyer ve flying fish gibi şişme araçlar, Waterblob, scuba dalışı, deepflight super falcon, Seabob olmak üzere pek çok çeşidi bulunmaktadır (Uyanik, 2019).

1990'lı yıllarda özellikle otel ve tatil köyleri içinde ve dışında artmaya başlayan su sporları işletmelerinin sayısı günümüzde yaklaşık 700 adete ulaşmıştır. Su sporları aktivitelerinin yıllık 150 milyon dolar gelir yarattığı tahmin edilmektedir (Deniz Ticaret Odas1, 2012).

Türkiye'nin sörf, tüplü ya da tüpsüz dalış, yelken, su kayağı ve çeşitli deniz araçlarıyla yapılan su sporları açısından önemli bir potansiyeli bulunmaktadır. Örneğin; Alaçatı (Çeşme), Bodrum, Akyarlar (Marmaris), Gökçeada, Ayvalık, Kilyos gibi yerler özellikle rüzgâr sörfü açısından elverişli koşullara sahiptir. Bunun yanı sıra, Saros Körfezi, Kaş, Bodrum, Fethiye, Kalkan gibi yerlerde de dalış yapılabilmektedir. Bunun yanı sıra Türkiye'nin pek çok tatil beldesinde su sporları (sürat motoru, jet ski, su kayağı, banana v.b.) imkânları mevcuttur. Ancak, turistlere macera yaşama olanağ sunan bu sporlar zaman zaman kazalara neden olmakta ve bu kazalarda can ve mal kaybı yaşanabilmektedir.

Türk Dil Kurumu Sözlüğünde (2019) kaza, "istem dışı veya umulmayan bir olay dolayısıyla bir kimsenin, bir nesnenin veya bir aracın zarara uğraması" olarak tanımlanmaktadır. Kazalar, çevresel ya da bireysel birçok etkenden kaynaklanmaktadır. Kazaların meydana gelmesinde çevre koşullarının yanı sıra sosyolojik, psikolojik ve fizyolojik birçok etken de rol oynamaktadır (Barlas, 2011).

Kaza nedenlerini, tehlikeli durumları oluşturan çevresel faktörler ve tehlikeli davranışlara neden olan kişisel faktörler olarak iki ana başlık altında toplamak mümkündür. Kişisel faktörler; yetersiz bilgi ve yetenek, yetersiz fiziksel güç, yetersiz motivasyon, psikolojik ya da zihinsel sorunlar şeklinde sıralanabilir. Çevresel faktörler ise hatalı makine, uygun olmayan çalışma standartları, uygun olmayan çalışma yöntemi gibi nedenlerden kaynaklanmaktadır. Kazaların önlenmesi için yapılacak çalışmalarda kişisel ve fiziksel nedenlerin birlikte ele alınıp değerlendirilmesi ve hem kişisel faktörlerin hem de tehlikeli çevresel faktörlerin belirlenerek ortadan kaldırılması 
gerekmektedir (Barlas, 2011). Bu durum turistlerin can ve mal güvenliğinin sağlanması açısından büyük önem taşımaktadır. Bu bağlamda bu çalışmada Türkiye'de meydana gelen su sporları kazaları incelenmekte, kaza nedenleri analiz edilmekte ve bu kazaların azaltılabilmesi için öneriler sunulmaktır.

\section{Yöntem}

Türkiye'de meydana gelen su sporları kazaları ile ilgili olarak resmi bir veri (Türkiye İstatistik Kurumu- TÜİK dahil) bulunmamaktadır. Ayrıca, literatürde de bu konu ile ilgili herhangi bir çalışma yer almamaktadır. Bu nedenle bu çalışmada 19972019 tarihleri arasında internet sitelerinde ve gazetelerin internet sayfalarında yer alan ölümlere ve yaralanmalara neden olan kazalar incelenerek 22 y1l boyunca denizde meydana gelen su sporları kazaları istatistiği oluşturulmuştur.

Çalışma Mart-Nisan 2019 döneminde araştırmacılar tarafından gerçekleştirilmiştir. $\mathrm{Bu}$ bağlamda 48 internet sitesi incelenmiş ve bu haber kaynaklarında yer alan su sporları kazaları ile ilgili 59 haber toplanmıştır. Elde edilen bilgiler içerik analizi ile analiz edilmiş ve bu kazalar listelenmiştir. Ayrıca bu kazaların cinsiyete, yaşa, kazanın olduğu güne, kullanılan deniz aracına ve kıyıya olan uzaklığına göre dağılımları ise yüzdesel olarak gösterilmiştir.

\section{Bulgular}

Araştırma sonucunda elde edilen kazaların illere göre dağılımı Şekil 1'de verilmiştir. Kaydedilen ölümlere ve yaralanmalara sebep olan kazalar ise Tablo 1'de listelenmiştir.

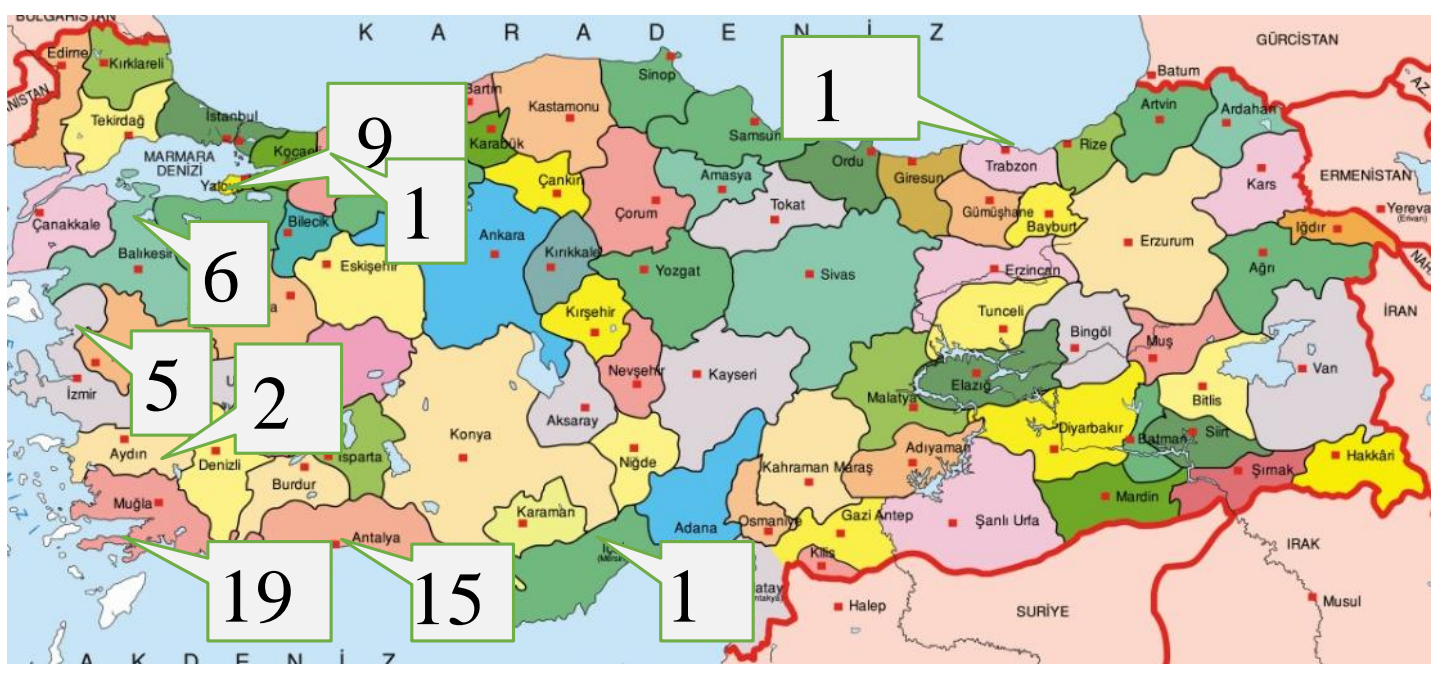

Şekil 1: Türkiye'de Meydana Gelen Ölümcül Deniz Sporları Kazalarının İllere Göre Dağılımı (1997-2019)

Çalışma, 1997-2019 yılları arasında meydana gelen su sporları kazalarının sırasıyla en çok Muğla, Antalya ve İstanbul'da vuku bulduğunu göstermektedir. Bu illerden Antalya ve Muğla özellikle kıyı turizminin geliştiği turizm merkezleri olarak daha çok kazalara sahne olmaktadır. 
Tablo 1 kazaların meydana geldiği bölgeleri göstermektedir. Kazaların meydana geldiği bölgeler; kumsal, yakın sahil ve açık sahil olmak üzere üçe ayrılmıştır. Kumsal ile tanımlanan bölge karadan denize doğru çok yakın bir mesafeyi (yaklaşık 5 metre), yakın sahil ile tanımlanan bölge kumsal bölgesinden sonraki yaklaşık 10 metreyi ve açık sahil ile tanımlanan bölge ise yakın sahil bölgesinin ilerisini ifade etmektedir.

Tablo 1. Türkiye'de Meydana Gelen Ölümcül Su Sporları Kazaları (1997-2019)

\begin{tabular}{|c|c|c|c|c|c|}
\hline No & 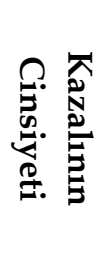 & 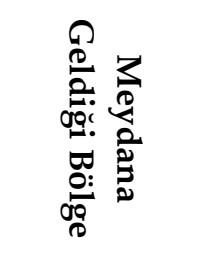 & 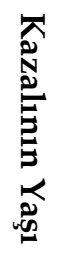 & Notlar & 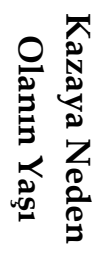 \\
\hline 1 & K & Yakın Sahil & 22 & 1 ölü, 1 yaralı, sürat teknesinin çarpması & - \\
\hline 2 & $\mathrm{E}$ & Yakın Sahil & 30 & Ağır yaralı, sürat teknesinin çarpması & - \\
\hline 3 & E & Açık Sahil & 18 & $\begin{array}{l}\text { Ölüm, balık avlarken sürat teknesinin } \\
\text { çarpması }\end{array}$ & - \\
\hline 4 & $\mathrm{E}$ & Açık Sahil & 17 & $\begin{array}{l}1 \text { ölüm, sürat teknesinin dalgasıyla diğer } \\
\text { teknenin batması }\end{array}$ & - \\
\hline 5 & E & Açık Sahil & 40 & Ölüm, sürat teknesinin çarpması & - \\
\hline 6 & $\mathrm{E}$ & Açık Sahil & 17 & Ölüm, tekne çarpması & 21 \\
\hline 7 & E & Açık Sahil & 44 & $\begin{array}{l}\text { Ölüm, dalış esnasında sürat teknesinin } \\
\text { çarpması }\end{array}$ & 48 \\
\hline 8 & E & Kumsal & 25 & Ölüm, jet skiden düşme sonucu kafa travması & - \\
\hline 9 & E & Yakın Sahil & 25 & 1 ölü, jet skiden düşme & 25 \\
\hline 10 & $\mathrm{E}$ & Açık Sahil & 28 & $\begin{array}{l}\text { 1ölü, } 1 \text { ağır yaralı, bottan düşenlere teknenin } \\
\text { çarpması }\end{array}$ & - \\
\hline 11 & $\mathrm{E}$ & Açık Sahil & 30 & 2 yaralı, jet-skinin tekneye çarpması & 29 \\
\hline 12 & E & Açık Sahil & 39 & 1 ölü, parasailing kemerinin çıkartılması & 39 \\
\hline 13 & E & Açık Sahil & 52 & Yaralı, sürat teknesinin çarpıp kaçması & - \\
\hline 14 & E & Açık Sahil & 57 & $\begin{array}{l}1 \text { ölü, } 1 \text { ağır yaralı, jet skiyle demirlenmiş yata } \\
\text { çarpılması }\end{array}$ & - \\
\hline 15 & $\mathrm{E}$ & Kumsal & 24 & $\begin{array}{l}\text { Yaralı, jet ski çarpması sonucu başından } \\
\text { yaralanma }\end{array}$ & 22 \\
\hline 16 & $\mathrm{E}$ & Yakın Sahil & 24 & 1 ağır yaralı, jet ski çarpması & 22 \\
\hline 17 & E & Yakın Sahil & 17 & A ğır yaralı, jet skilerin çarpışması & - \\
\hline 18 & E & Yakın Sahil & 17 & 1 ağır yaralı, jet ski çarpışması & 18 \\
\hline 19 & E & Yakın Sahil & 37 & 1 yaralı, Zodyak botun üzerinden geçmesi & 29 \\
\hline 20 & $\mathrm{~K}$ & Yakın Sahil & - & Yaralı (4 kırık kaburga), Jet skilerin çarpışması & - \\
\hline 21 & $\mathrm{~K}$ & Yakın Sahil & 13 & Ağır yaralı, jet ski çarpması & 30 \\
\hline 22 & $\mathrm{E}$ & Kumsal & & 1 ölü, jet skiden savrulma & - \\
\hline
\end{tabular}




\begin{tabular}{|c|c|c|c|c|c|}
\hline 23 & E & Açık Sahil & 54 & $\begin{array}{l}5 \text { yaralı, } 1 \text { ölü, sürat teknesinin demirlemiş } \\
\text { tekneye çarpması }\end{array}$ & 38 \\
\hline 24 & K & Yakın Sahil & 34 & 1 ölü,1 ağır yaralı, jet ski çarpması & 31 \\
\hline 25 & K & Yakın Sahil & 34 & 1 ölü,1 ağır yaralı, jet skinin bot ile çarpışması & - \\
\hline 26 & $\mathrm{E}$ & Açık Sahil & - & 1 yaralı, parasailing paraşütünün ters dönmesi & - \\
\hline 27 & E & Yakın Sahil & 47 & Jet skilerin çarpışması & $35-47$ \\
\hline 28 & E & Yakın Sahil & & 1 ölü, jet skinin çarpması & - \\
\hline 29 & $\mathrm{E}$ & Yakın Sahil & 57 & 1 ölü, jet skinin çarpması & - \\
\hline 30 & K & Yakın Sahil & 60 & Ölüm, sürat teknesinin çarpması & 34 \\
\hline 31 & K & Yakın Sahil & 22 & $\begin{array}{l}1 \text { ölü,1 ağır yaralı, bananadan düşme sonucu } \\
\text { kafanın demire çarpması }\end{array}$ & 30 \\
\hline 32 & K & Açık Sahil & 22 & 2 yaralı, banana adlı eğlence aracından düşme & - \\
\hline 33 & K & Yakın Sahil & 23 & Ölüm, su sporları yapan sürat teknesi & 29 \\
\hline 34 & E & Yakın Sahil & - & 2 yaralı, sürat teknesi-kayık çarpışması & - \\
\hline 35 & $\mathrm{E}$ & Yakın Sahil & - & 1 ağır yaralı, sürat teknesinin çarpması & 48 \\
\hline 36 & $\mathrm{E}$ & Yakın Sahil & - & 2 yaralı, jet skinin devrilmesi & - \\
\hline 37 & $\mathrm{E}$ & Yakın Sahil & 21 & 1 ağır yaralı, sürat teknesi & - \\
\hline 38 & E & Açık Sahil & 38 & 1 ölü, kontrol teknesi ile sürat & - \\
\hline 39 & K & Açık Sahil & 19 & 2 yaralı, jet skilerin çarpışması & 44 \\
\hline 40 & E & Açık Sahil & 74 & 4 yaralı, parasailing halatının kopması & - \\
\hline 41 & E & Kumsal & 33 & 2 ölü, 1 yaralı, Sürat teknesi kazası & 33 \\
\hline 42 & E & Yakın Sahil & 23 & 1 yaralı, jet skiden düşme & 23 \\
\hline 43 & K & Yakın Sahil & 16 & 2 ağır yaralı, jet skinin gulete çarpması & - \\
\hline 44 & E & Açık Sahil & - & 2 yaralı, sürat teknesi motor yangını & - \\
\hline 45 & K & Açık Sahil & 29 & 2 yaralı, parasailing paraşütünün ters dönmesi & - \\
\hline 46 & $\mathrm{E}$ & Açık Sahil & - & 2 yaralı, parasailing halatının kopması & - \\
\hline 47 & E & Açık Sahil & 34 & 1 ölü, sürat teknesi kazası & - \\
\hline 48 & E & Yakın Sahil & - & 1 ölü, jet skilerin çarpışması & - \\
\hline 49 & $\mathrm{E}$ & Açık Sahil & - & $\begin{array}{l}4 \text { yaralı, sürat teknesi ile balıkçı teknesinin } \\
\text { çarpışması }\end{array}$ & - \\
\hline 50 & $\mathrm{E}$ & Açık Sahil & 54 & 1 ölü, sürat teknesinin çarpması & - \\
\hline 51 & $\mathrm{E}$ & Yakın Sahil & - & $\begin{array}{l}1 \text { hafif yaralı, sürat teknesinin dalga kırana } \\
\text { çarpması }\end{array}$ & - \\
\hline 52 & $\mathrm{E}$ & Açık Sahil & - & $\begin{array}{l}2 \text { ağır yaralı (\%35 oranında yanıklar), sürat } \\
\text { teknesi }\end{array}$ & - \\
\hline 53 & $\mathrm{E}$ & Açık Sahil & 12 & 1 ölü, parasailing halatının kopması & - \\
\hline 54 & $\mathrm{E}$ & Kumsal & 63 & 1 yaralı, jet ski kazası & 63 \\
\hline 55 & E & Kumsal & - & 2 yaralı, jet ski kazası & - \\
\hline 56 & $\mathrm{E}$ & Yakın Sahil & - & 1 ölü, jet skilerin çarpışması & - \\
\hline 57 & K & Açık Sahil & - & $\begin{array}{l}\text { A ğır yaralı (kaburga kırıkları ve omurga } \\
\text { çatlağı), sürat teknesinin çarpması }\end{array}$ & - \\
\hline
\end{tabular}




\begin{tabular}{|l|l|l|c|l|c|}
\hline 58 & E & Yakın Sahil & - & 3 yaralı, jet ski ile sürat teknesinin çarpışması & - \\
\hline 59 & K & Kumsal & - & 4 yaralı, jet skinin kumsala çıkması & - \\
\hline
\end{tabular}

Kazaların 27 tanesi yakın sahilde, 25 tanesi açık sahilde, 7 tanesi ise kumsalda meydana gelmiştir. Kazaların 27 tanesi ölümle, 39 tanesi yaralanma ile sonuçlanmıştır.

Şekil 2'de 1997-2019 yılları arasında Türkiye'de meydana gelen deniz kazalarının kıyıya olan mesafelerine göre dağılımı verilmiştir. Buna göre deniz kazalarının yaklaşık yarısı yakın sahil bölgelerinde meydana gelmiştir. Kazaların \%12'si ise kumsala çok yakın bir bölgede gerçekleşmiştir. Kumsal yakınında meydana gelen deniz kazalarının neredeyse tamamı jet ski kazalarıdır. Parasailing kazalarının büyük bir çoğunluğu açık sahilde meydana gelmiştir. Sürat teknesi kazaları ise yakın ve açık sahilde gerçekleşmiştir.

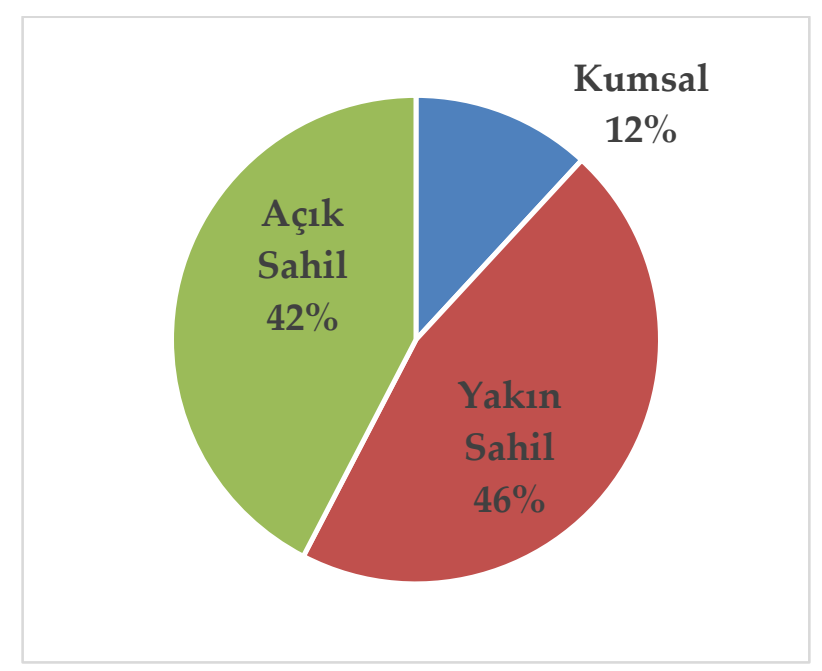

Şekil 2. Türkiye'de Meydana Gelen Su Sporları Kazaların Kıyıya Olan Mesafelerine Göre Dağılımı (1997-2019)

Şekil 3'de 1997-2019 yılları arasında Türkiye'de meydana gelen ölümcül sürat teknesi, jet ski kazalarının cinsiyete göre dağılımı verilmiştir. Bu kazalarda erkeklerin ölüm oranı \%76, kadınların ise \%24'tür. Bu durum erkeklerin daha çok ölümlü jet ski kazalarına neden olduklarını göstermektedir.

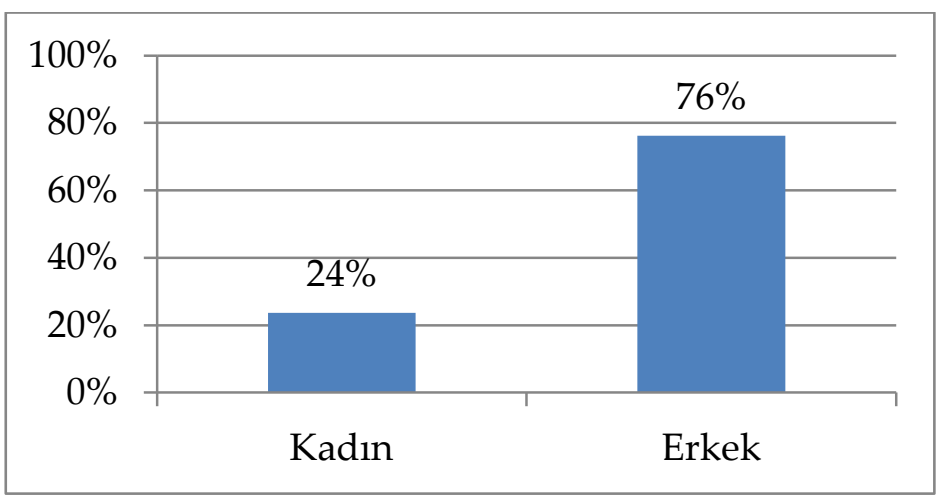

Şekil 3. Türkiye'de Meydana Gelen Ölümcül Sürat Teknesi, Jet ski Kazalarının Cinsiyete Göre Dağılımı (1997-2019) 
Şekil 4'te 1997-2019 yılları arasında Türkiye'de meydana gelen ölümcül sürat teknesi, jet-ski kazalarının haftanın günlerine göre dağılımı verilmiştir. Bu kazalar genellikle hafta sonlarında meydana gelmektedir. Kazaların en çok meydana geldiği gün ise Pazar günüdür. Yerli turistlerin tatil olması nedeniyle daha çok turistik faaliyete katılması hafta sonlarında yaşanan kaza sayısını arttırmaktadır. Bu bağlamda kazaların önlenmesi için özellikle hafta sonlarında alınan önlemler arttırılmalıdır.

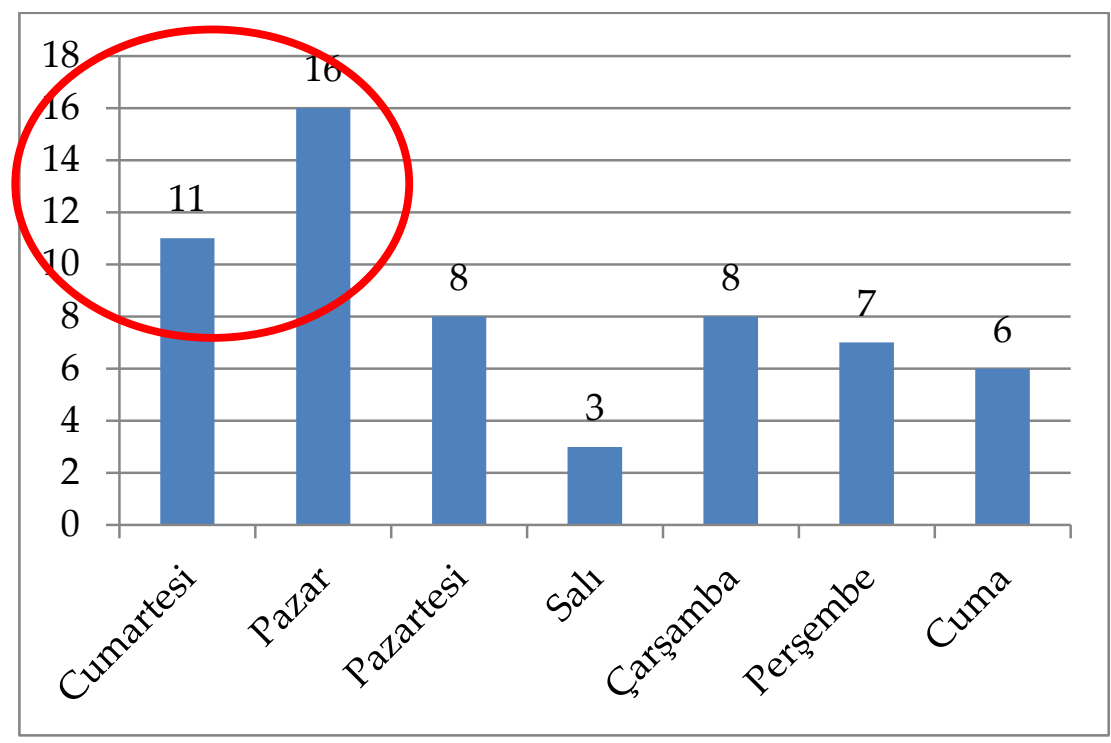

Şekil 4. Türkiye'de Meydana Gelen Ölümcül Sürat Teknesi, Jet ski Kazalarının Günlere Göre Dağ1lımı (1997-2019)

Şekil 5'te 1997-2019 yılları arasında Türkiye'de meydana gelen ölümcül jet ski kazalarının yaş gruplarına göre dağılımı görülmektedir. Kazaların en çok \%24 oranıla 19-25 yaş aralığında gerçekleştiği ve 56 yaş ve üzerinde olan bireylerin (\%20) kazalara neden olduğu görülmektedir. Ayrıca kazaların \%60'1 35 yaş altı grubunda bulunan bireyler tarafından yapılmıştır.

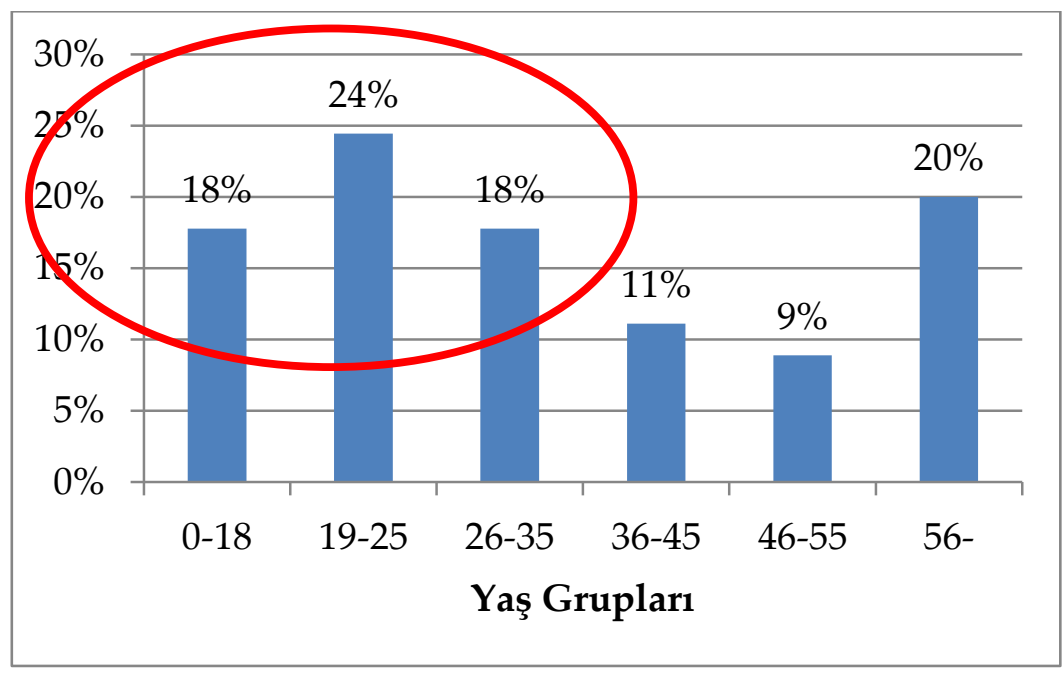

Şekil 5. Türkiye'de Meydana Gelen Ölümcül Sürat Teknesi, Jet ski Kazalarının Yaş Gruplarına Göre Dağılımı (1997-2019) 
Şekil 6, 1997-2019 yılları arasında Türkiye'de meydana gelen ölümcül sürat teknesi, jet ski ve diğer kazaların dağılımını göstermektedir. Kazaların büyük bir kısmı $\% 44$ oranında jet-ski ve $\% 42$ oranında sürat teknesi kazalarından meydana gelmektedir.

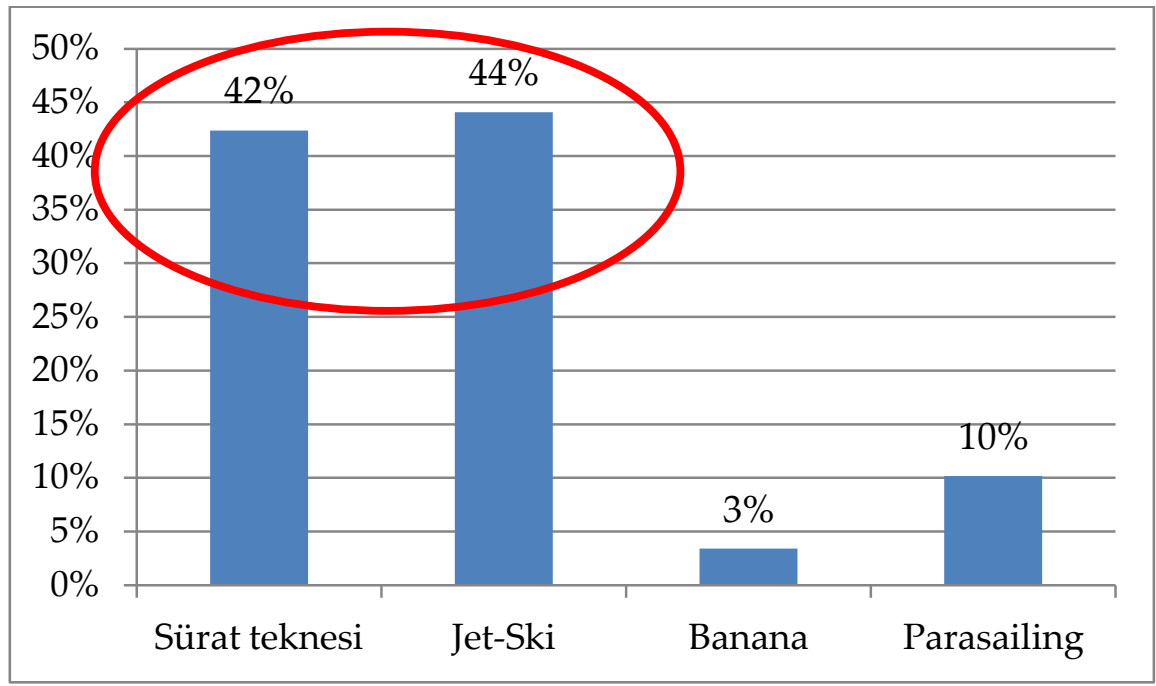

Şekil 6. Türkiye'de Meydana Gelen Ölümcül Sürat Teknesi, Jet ski Kazalarının Deniz Araçlarına Göre Dağılımı (1997-2019)

Tablo 2, 1997-2019 yılları arasında meydana gelen sürat tekneleri, jet ski, banana, parasailing kazalarının nedenlerini göstermektedir:

Tablo 2. Sürat Tekneleri, Jet ski, Banana ve Parasailing Kazalarının Nedenleri (1997-2019)

\begin{tabular}{|l|l|l|l|}
\hline Sürat Tekneleri & \multicolumn{1}{|c|}{ Jet ski } & \multicolumn{1}{c|}{ Banana } & \multicolumn{1}{c|}{ Parasailing } \\
\hline $\begin{array}{l}\text { Aşırı hız ve } \\
\text { buna bağlı } \\
\text { olarak görüş } \\
\text { kaybı }\end{array}$ & $\begin{array}{l}\text { Ters dalga } \\
\text { sonucu alabora } \\
\text { olma }\end{array}$ & $\begin{array}{l}\text { Ani manevralar } \\
\text { sonucu savrulmaların } \\
\text { yaşanması }\end{array}$ & $\begin{array}{l}\text { Emniyet kemerinin } \\
\text { gerektiği gibi } \\
\text { takılmaması, } \\
\text { çıkarılması }\end{array}$ \\
\hline Dikkatsizlik & $\begin{array}{l}\text { Ani manevralar } \\
\text { sonucu düşme }\end{array}$ & $\begin{array}{l}\text { Diğer deniz } \\
\text { araçlarıyla yakın } \\
\text { yerlerde kullanılması } \\
\text { sonucu çarpışma }\end{array}$ & $\begin{array}{l}\text { Havadayken akrobatik } \\
\text { hareketlerde } \\
\text { bulunulması }\end{array}$ \\
\hline $\begin{array}{l}\text { Bilgi eksikliği } \\
\text { (eğitimsizlik, } \\
\text { ehliyetsiz } \\
\text { kullanım) }\end{array}$ & $\begin{array}{l}\text { Eŭlence amaçlı } \\
\text { kullanılan diğer } \\
\text { araçlarla } \\
\text { çarpışma } \\
\text { (banana, sürat } \\
\text { tekneleri, şişme } \\
\text { botlar vb.) }\end{array}$ & $\begin{array}{l}\text { Can yeleklerinin } \\
\text { kullanılmaması }\end{array}$ & $\begin{array}{l}\text { Kullanılan halatın } \\
\text { kopması }\end{array}$ \\
\hline $\begin{array}{l}\text { Alkollü } \\
\text { kullanma }\end{array}$ & $\begin{array}{l}\text { Yaş ehliyeti } \\
\text { olmayan kişilerin } \\
\text { kullanması }\end{array}$ & $\begin{array}{l}\text { Sürat teknesi ile } \\
\text { banana arasındaki } \\
\text { halatın mesafesinin } \\
\text { kısa olması }\end{array}$ & $\begin{array}{l}\text { Hava koşullarının } \\
\text { dikkate alınmadığı } \\
\text { durumlarda paraşütün } \\
\text { ters dönmesi }\end{array}$ \\
\hline
\end{tabular}




\begin{tabular}{|l|l|l|l|}
\hline $\begin{array}{l}\text { Teknik açıdan } \\
\text { yetersiz tekne } \\
\text { kullanımı }\end{array}$ & $\begin{array}{l}\text { Şov amaçlı } \\
\text { kullanma }\end{array}$ & $\begin{array}{l}\text { Çocuk yaşta kişilerin } \\
\text { binmesine izin } \\
\text { verilmesi }\end{array}$ & $\begin{array}{l}\text { Ters rüzgâr sebebiyle } \\
\text { paraşütün düşmesi }\end{array}$ \\
\hline $\begin{array}{l}\text { İnsanların } \\
\text { yüzmek için } \\
\text { belirlenen } \\
\text { alanları aşmaları }\end{array}$ & $\begin{array}{l}\text { Belirlenen sınırlar } \\
\text { dışında kullanma }\end{array}$ & & $\begin{array}{l}\text { Parasailingde } \\
\text { kullanılan sürat } \\
\text { teknesinin bilinçsizce } \\
\text { ve eğitimsiz kişilerce } \\
\text { kullanımı }\end{array}$ \\
\hline & & & $\begin{array}{l}\text { Çocuk yaştaki kişilerin } \\
\text { parasailing yapmasına } \\
\text { izin verilmesi }\end{array}$ \\
\hline
\end{tabular}

Tablo 2 incelendiğinde meydana gelen bu kazaların nedenlerinin aşırı hız, dikkatsizlik, bu araçları çocuk yaştaki kişilerin kullanması, hava koşulları, su sporları araçlarının bakım ve onarımlarının periyodik olarak yapılmaması ile araçların teknik yetersizlikleri olduğu görülmektedir.

\section{Sonuç ve Öneriler}

Bu çalışmada 1997-2019 yılları arasında Türkiye'de meydana gelen su sporları kazaları Google araştırma sistemi, internet haberleri ve gazetelerin internet sitelerinde yer alan haberler kullanılarak incelenmiştir. Çalışmadan elde edilen sonuçlar aşağıda verilmektedir:

- Türkiye'de denizde meydana gelen su sporları kazaları genel olarak değerlendirildiğinde, meydana gelen kazaların ve ortaya çıkan risklerin insan ihmalleri, teknik aksaklıklar, doğal koşulların hesaba katılmaması, planlama ve denetim eksikliğinden kaynaklandığ görülmektedir.

- Kazaların 3/4'ü Ege ve Akdeniz sahillerinde yer alan turizm merkezlerinde meydana gelmiştir.

- Ölüm ve/veya yaralanma ile sonuçlanan kazaların \%44'ü jetski, \% 42'si ise sürat teknesi kazalarıdır. Bu durum kazaların en çok jet skinin hatalı kullanımından kaynaklandığını göstermektedir.

- Kazaların 1/4'ü 19-25 yaş aralığında olan kişiler tarafından yapılmaktadır. Bu durum özellikle genç yaştaki kişilerin riskli grubu oluşturduklarını göstermektedir.

- Kazaların 1/3'ü Pazar günü meydana gelmekte, ölümlü kazaların ise en çok hafta sonları olduğu görülmektedir.

- Kazaya neden olan kişiler cinsiyetleri bakımından incelendiğinde; ağırlıklı olarak erkeklerin daha çok kazaya karıştıkları görülmektedir.

- Kazaların meydana geldiği bölgeler genellikle sahilden açıkta olan ya da sahile yakın yerlerdir.

Türkiye'de meydana gelen su sporları kazalarının önlenmesi ve risklerin en aza indirilmesi için pek çok önlem alınabilir. Bu bağlamda mutlaka insanların bilinçlendirilmesi/eğitilmesi, kullanılan spor aletleri ve ekipmanların teknik donanımlarının yeterli olması, gerekli bakım ve kontrollerinin düzenli olarak yapılması gerekmektedir. 
Bu kazaların önlenmesinde sürat tekneleri ile ilgili olarak;

(1) Öncelikle bu araçların CE ve ISO standartlarına uygun olması gerekmektedir.

(2) Teknelerde kullanılan gaz sistemleri, tesisat boruları, yakıt sistemleri ve elektrik sistemlerinin hepsi ayrı ayrı güvenlik standartlarından geçmeli, bu teknelerin düzenli olarak kontrolleri yapılmalıdır. Bu kontroller yasalarca belirlenmiş olmasına rağmen, uygulamada karşılaşılan sorunlar nedeniyle kontrol edenin ve kontrol ettirenin yasalara uymasını engelleyecek her türlü katı tedbirlerin alınması gerekmektedir.

(3) Sürat teknesini kullanacak kişilerin gerekli eğitimleri almış olmaları ve gerekli tecrübe elde edilene kadar uygulama çalışmalarına katılmaları sağlanmalıdır. Bu bağlamda sürat teknesi kullanacak kişilerin belgeleri tam olsa bile deneyimli kişiler eşliğinde tecrübe edinmeleri sağlanmalıdır.

(4) Bu tür deniz araçları çocuklara asla kullandırılmamalıdır. Bu tür bir durumlarla karşılaşıldığında kullanana ve kullandırana ayrı ayrı olmak üzere caydırıcı cezalar uygulanmalıdır.

(5) Sürat teknesini kullanan kişinin karar verme ve kontrol mekanizmasını etkileyecek uykusuzluk, yorgunluk hallerine dikkat etmesi, alkol, uyuşturucu, dikkat dağınıklığına sebep olan herhangi bir tıbbi ilacı kullanmaması gerekir.

(6) Sürat teknelerinin hareket alanına giren bölgelerde yüzen kişiler uyarılmalı ve gerekirse cezalandırılmalıdır. Ayrıca bu tür alanlara girişi önlemek için görevli cankurtaran bilinçlendirilmeli ve insanları uyarmalıdır.

(7) Bölge yönetmeliklerinde belirtilen hız sınırları aşılmamalıdır. Ayrıca kiralama durumlarında sürat teknelerine hız sınırlayıcı donanım takılmalıdır.

(8) Sürat teknesi içinde standartlara uygun el maytabı, duman kandili, gps, dürbün, kişi sayısı kadar can yeleği, çocuk sayısı kadar çocuk can yeleği, ışıklı can simidi, amatör denizci el kitabı vs. bulundurulması gerekmektedir.

(9) Seyir esnasında can yeleklerinin kullanılmasına azami dikkat edilmelidir.

(10) Sürat teknelerinin birbiriyle ve diğer deniz araçlarıyla ya da kıyıdaki çarpışmaları önleyecek şekilde etkili bir ikaz sistemi ile donatılması gerekmektedir.

Bu kazaların önlenmesinde jet skilerle ile ilgili olarak;

(1) Jet ski kullanılırken can yeleğinin giyilmesi,

(2) Seyir esnasında kontrolü zorlaştıracak her türlü ani manevralardan kaçınılması,

(3) Kullanım menzili dışına çıkılmaması,

(4) Şov amaçlı akrobatik hareketlerin yapılmaması,

(5) Bu araçların yaş ehliyeti olmayanlara kullandırılmaması, 
(6) Belirlenen yaş sınırı altındakilerle birlikte jet skiye binilmemesi,

(7) Patlama ve yangınların sebep olduğu kazaların önüne geçilmesi için jet skilerin periyodik bakım ve kontrollerinin yapılması ve yetkili kurum ve kuruluşlar tarafından bakımlarının yapılıp yapılmadı̆̆ının denetlenmesi,

(8) Diğer eğlence araçlarının ve insanların yüzdüğü yerlerde jet ski kullanımının yasaklanması,

(9) Uygun olmayan hava şartlarında jet ski kullanılmaması,

(10) Jet ski kullanan kişinin karar verme ve kontrol mekanizmasını etkileyecek uykusuzluk, yorgunluk hallerine dikkat etmesi, alkol, uyuşturucu ve dikkat dağınıklığına sebep olan herhangi bir tıbbi ilacı kullanmaması gerekir.

Parasailing ile ilgili olarak;

(1) İşletmeci ve kullanıcıların bilinçlendirilmesi,

(2) Emniyet kemeri kullanımına özen gösterilmesi,

(3) Denizde insan yoğunluğun olduğu alanlarda bu sporun yaptırılmaması,

(4) Teknik araçların düzenli kontrolünün yapılması,

(5) Herhangi bir savrulma durumunda düşen kişiler için önceden hazırlanmış bir eylem planının olması,

(6) Uygun olmayan hava koşullarında kullanılmaması gerekmektedir.

Banana ile ilgili olarak;

(1) Sürat teknesini kullanan kişinin bu aracı kullanma yetkisinin olması,

(2) Can yeleksiz bananaya binilmemesi,

(3) İnsan yoğunluğunun olduğu yerlerde çarpışmaları önlemek için farklı rotaların belirlenmesi,

(4) Çocuk yaştaki kişilerin bu araçlara hiçbir koşulda bindirilmemesi,

(5) Pervane kısmında yaralanmalara sebep olunmaması için sürat teknesi ile banana arasında bulunan halatın yeterli uzunlukta olması, bu halatların çekme dayanımlarının düzenli olarak kontrol edilmesi ve eski, yıpranmış halatların kullanılmaması gerekmektedir.

$\mathrm{Bu}$ çalışmada sunulan öneriler, sahil belediyelere, su sporları işletmelerine, su sporlarına katılan turistlere yol gösterici olacaktır. Yerel yönetimler ve su sporları işletmecileri, bu önerileri dikkate alarak turistlerin güvenliğini daha etkin bir biçimde sağlayabilir, bu tür kazaları önleyebilir ya da en azından azaltabilirler. Bundan sonra yapılacak olan çalışmalarda; bu çalışmadan elde edilen sonuçlar kullanılarak su sporları kazalarını önlemek için alınması gerekli tedbirlerin öncelik sıralaması belirlenebilir. 


\section{Kaynakça}

Barlas, B. (2011). Gemi İnşaatı Sanayinde İş Kazaları ve En Aza İndirmek İçin Alınması Gerekli Tedbirler, TMMOB Gemi Mühendisleri Odası, İstanbul.

Deniz Ticaret Odası (2015). Deniz Turizmi Dergisi, Deniz Turizminin Dünü, Bugünü ve Sürdürülebilirliği.

Paker, S. (2013). Denizde Sportif Faaliyetler, Denizcilik İşletmeleri Yönetimi.

Türk Dil Kurumu Sözlüğ̈ (2019). http://sozluk.gov.tr/

Uyanık, B. (2019). Türkiye'de Deniz Turizmi Kazaları ve Kazaların En Aza İndirilmesi İçin Genel Değerlendirme, İstanbul Teknik Üniversitesi Gemi İnşaatı ve Deniz Bilimleri Fakültesi Bitirme Tasarım Projesi , İstanbul, Mayıs 2019.

İncelenen İnternet Siteleri:

URL-1 http://www.hurriyet.com.tr/uzerinden-surat-teknesi-gecen-genc-kadin-yarala40917350, Erişim Tarihi: 15 Nisan 2019

URL-2 http://www.cumhuriyet.com.tr/video/video_haber/811595/Bodrumdasurat_teknes

i_cayir_cayir_yandi_2_yarali.html, Erişim Tarihi: 15 Nisan 2019

URL-3 http://www.hurriyet.com.tr/gundem/kusadasinda-gorunmez-kaza-40235575,

Erişim Tarihi: 15 Nisan 2019

URL-4 https://www.haberler.com/izmir-dikilli-tekne-kazasindaki-dort-kisiyi-sahil-

8771856-haberi, Erişim Tarihi: 15 Nisan 2019

URL-5 https://www.haberturk.com/yerel-haberler/haber/8814429-karasuda-suratteknesi-dalgakiranin-ustune-cikti, Erişim Tarihi: 15 Nisan 2019

URL-6 https://www.cnnturk.com/turkiye/istanbul-bogazinda-kaza, Erişim Tarihi: 15 Nisan 2019

URL-7 https://www.turkiyegazetesi.com.tr/yasam/299451.aspx, Erişim Tarihi: 15 Nisan 2019

URL-8 http://www.milliyet.com.tr/zipkinla-avlanan-balikciya-tekne-carpti-antalyayerelhaber-1071139, Erişim Tarihi: 15 Nisan 2019

URL-9 https://www.haberdenizli.com/guncel/dalyan-kanalinda-tekne-kazasi-1-oluh10655.html, Erişim Tarihi: 15 Nisan 2019

URL-10 https://www.sabah.com.tr/yasam/2013/05/31/kayik-sefasi-faciayla-bitiyordu, Erişim Tarihi: 15 Nisan 2019

URL-11 https://www.memurlar.net/haber/410643/surat-teknesinden-dusen-gencin-dalagipatladi.html, Erişim Tarihi: 15 Nisan 2019

URL-12 http://www.fethiyehaber.com/tekne-kaptani-tutuklandi/ 
URL-13 https://www.sabah.com.tr/yasam/2012/07/29/edremitte-surat-teknesi-faciasi-1-olu, Erişim Tarihi: 15 Nisan 2019

URL-14 http://www.hurriyet.com.tr/gundem/surat-teknesinin-carptigi-universiteli-genckiz-oldu-21215082, Erişim Tarihi: 15 Nisan 2019

URL-15 http://www.hurriyet.com.tr/gundem/isadami-yeni-teknesinde-oldu-18641220, Erişim Tarihi: 15 Nisan 2019

URL-16 https://www.yenisafak.com/gundem/kiyida-dalan-doktoru-surat-teknesi-bicti124881, Erişim Tarihi: 15 Nisan 2019

URL-17 http://arsiv.sabah.com.tr/2004/07/25/gun115.html, Erişim Tarihi: 15 Nisan 2019

URL-18 http://www.hurriyet.com.tr/ege/babanin-hukuk-savasi-39122805, Erişim Tarihi: 15 Nisan 2019

URL-19 http://www.hurriyet.com.tr/gundem/denizde-ringo-kazasi-2-kisi-dustu-1i-oldu11766604, Erişim Tarihi: 15 Nisan 2019

URL-20 https://www.turkiyegazetesi.com.tr/Genel/a74511.aspx, Erişim Tarihi: 15 Nisan 2019

URL-21 http://www.hurriyet.com.tr/jet-ski-ile-banana-carpisti-avustralyali-bab-40938659, Erişim Tarihi: 15 Nisan 2019

URL-22 https://www.internethaber.com/antalyadan-gelen-haber-dehsete-dusurdudenizde-facia-1800718h.htm, Erişim Tarihi: 15 Nisan 2019

URL-23 http://www.hurriyet.com.tr/kelebek/magazin/unlu-isadami-ali-agaoglu-olumdendondu-helikopterle-istanbula-getirildi-40502321, Erişim Tarihi: 15 Nisan 2019

URL-24 http://www.hurriyet.com.tr/gundem/jet-ski-kazasinda-agir-yaralanan-ingilizgenc-9-gun-sonra-oldu-40213229, Erişim Tarihi: 15 Nisan 2019

URL-25 https://www.aa.com.tr/tr/spor/trabzonspor-kulubu-yku-engin-kara-jet-skikazasinda-yasamini-yitirdi/619838, Erişim Tarihi: 15 Nisan 2019

URL-26 http://www.milliyet.com.tr/surucusuz-jet-ski-karaya-cikti-kumsalda-antalyayerelhaber-962554/, Erişim Tarihi: 15 Nisan 2019

URL-27 https://www.takvim.com.tr/guncel/2015/07/21/olume-yelken-acti, Erişim Tarihi: 15 Nisan 2019

URL-28 http://www.hurriyet.com.tr/marmaris-te-jetsi-kazasi-1-i-agir-2-yarali-37155111, Erişim Tarihi: 16 Nisan 2019 
URL-29 http://www.hurriyet.com.tr/gundem/bodrumda-jet-ski-kazasi-2-yarali-26971508, Erişim Tarihi: 16 Nisan 2019

URL-30 https://www.haberler.com/alanya-da-jet-ski-kazasi-1-yarali-4594905-haberi, Erişim Tarihi: 16 Nisan 2019

URL-31 https://www.haberler.com/ayvalikta-jetski-kullanan-iki-arkadasi-olumden5007796-haberi, Erişim Tarihi: 16 Nisan 2019

URL-32 https://www.haberturk.com/gundem/haber/760934-ayvalikta-jet-ski-faciasi, Erişim Tarihi: 16 Nisan 2019

URL-33 https://www.cnnturk.com/2012/turkiye/05/13/isvecli.turist.jet.ski.kazasinda.oldu/6 60875.0/index.html, Erişim Tarihi: 16 Nisan 2019

URL-34 http://www.milliyet.com.tr/kanadali-turist-jet-ski-ile-bir-cocugu-yaraladigundem-1409922, Erişim Tarihi: 16 Nisan 2019

URL-35 https://www.ntv.com.tr/turkiye/bodrumda-jet-ski-kazasi-1olu,vTGu_WzCPEWWkz2UiFWQ2w, Erişim Tarihi: 16 Nisan 2019

URL-36 http://www.hurriyet.com.tr/gundem/erdekte-jet-ski-faciasi-18398616, Erişim Tarihi: 16 Nisan 2019

URL-37 http://www.cumhuriyet.com.tr/haber/diger/165616/Cesme_de_jetski_kazasi.html, Erişim Tarihi: 16 Nisan 2019

URL-38 https://www.haberler.com/cok-guzel-hareketler-in-gizem-i-jet-ski-kazasi-2162409haberi, Erişim Tarihi: 16 Nisan 2019

URL-39 https://www.haberler.com/dualar-can-guzelcan-icin-2169883-haberi, Erişim Tarihi: 16 Nisan 2019

URL-40 http://www.hurriyet.com.tr/gundem/jet-ski-faciasi-11677540, Erişim Tarihi: 16 Nisan 2019

URL-41 https://www.iha.com.tr/haber-muglada-jet-ski-kazasi-79362, Erişim Tarihi: 16 Nisan 2019

URL-42 https://www.cnnturk.com/2009/turkiye/08/07/parasailing.yapan.turist.denize.cakil di/538300.0/index.html, Erişim Tarihi: 16 Nisan 2019

URL-43 http://www.milliyet.com.tr/antalya-da-parasailing-kazasi-antalya-yerelhaber2122128, Erişim Tarihi: 16 Nisan 2019

URL-44 http://www.hurriyet.com.tr/gundem/ayvalikta-korkunc-kaza-30142840, Erişim Tarihi: 16 Nisan 2019 
B. Uyanık, N. Türker.../Karabük Üniversitesi Sosyal Bilimler Enstitüsü Dergisi, 2019, 9 (2), 457-471

URL-45 https://tr.sputniknews.com/yasam/201509081017609230, Erişim Tarihi: 16 Nisan 2019

URL-46 http://www.turizmaktuel.com/haber/antalya-da-parasailing-kazasi-4-turist-yarali, Erişim Tarihi: 16 Nisan 2019

URL-47 https://www.haberler.com/bodrum-1-doktorun-kabus-dakikalari-3726513-haberi, Erişim Tarihi: 16 Nisan 2019

URL-48 http://www.hurriyet.com.tr/gundem/sarigermede-banana-faciasi-21175307, Erişim Tarihi: 16 Nisan 2019. 